\title{
Aberrantly Conducted Complexes by ECG Finding
}

National Cancer Institute

\section{Source}

National Cancer Institute. Aberrantly Conducted Complexes by ECG Finding. NCI

Thesaurus. Code C116132.

An electrocardiographic finding of abnormal QRS complex(es) that are supraventricular in origin, and that are wide secondary to aberrant AV conduction. (CDISC) 